\title{
The Treatment of the Restless Legs Syndrome with Clonazepam: A Prospective Controlled Study
}

\author{
Dan Boghen, Lise Lamothe, Robert Elie, Roger Godbout and Jacques Montplaisir
}

\begin{abstract}
The effect of clonazepam on the restless legs syndrome was studied in a group of 6 patients. Following a drug-free period, 3 patients received clonazepam for 4 weeks followed by placebo for 4 weeks thereafter and 3 patients received the same medication and for the same length of time but in reverse order. The effectiveness of the medication was evaluated by means of a self-rating system in which patients assigned a score daily to the degree of discomfort experienced in the previous 24 hours. Three patients improved on clonazepam but 2 of these also improved on placebo. Clonazepam was not shown to be significantly more effective than placebo in the treatment of RLS.
\end{abstract}

RÉSUMÉ: L'effet du clonazepam dans le syndrome des jambes impatiences (le "syndrome des jambes sans repos") a été étudié chez 6 malades. Après une période de temps initiale sans traitement, 3 patients reçurent du clonazepam pour 4 semaines et du placebo pour 4 autres semaines alors que les 3 autres patients reçurent les mêmes médicaments et pour la même longueur de temps mais dans l'ordre inverse. L'efficacité du médicament fut déterminée à l'aide d'un système d'auto-évaluation permettant au patient d'allouer quotidiennement un score à la sévérité de ses symptômes au cours des 24 heures précédentes. Avec le clonazepam il y a eu amélioration des symptômes chez 3 des patients mais 2 d'entre-eux ont aussi été améliorés par le placebo. Dans cette étude le clonazepam ne s'est pas avéré être de façon significative plus efficace que le placebo dans le traitement du syndrome des impatiences des jambes.

Can. J. Neurol. Sci. 1986; 13:245-247

The restless legs syndrome (RLS) consists of ill-defined paresthesiae of the legs and an irresistible urge to move them. Leg myoclonus is a frequently associated feature. ' Characteristically the symptoms occur while the patient is sitting or lying down, especially at night, prior to falling asleep. Consequent severe insomnia may be a source of major distress. Based on recent data it would seem that the prevalence of the syndrome is as high as $1.2 \%$ in the general population and $5.9 \%$ among patients with a complaint of insomnia. ${ }^{2}$

There is no recognized effective treatment. Recently some measure of therapeutic success has been reported with carbamazepine ${ }^{3.4}$ and opioids. ${ }^{5.6}$ However, the drug which seems to be the most promising at the present time is clonazepam. ${ }^{7.8 .9 .10}$ The present preliminary study was undertaken in order to evaluate the effectiveness of clonazepam in the treatment of the restless legs syndrome in a prospective, double-blind and controlled manner.

\section{METHODS}

\section{Test Subjects}

Six patients suffering from the restless legs syndrome were studied over a period of three months in order to evaluate the effect of treatment with clonazepam.

The patients, 3 women and 3 men, 31 to 61 years old (average 46 years) complained of an irresistible urge to move the legs while at rest. Three of them experienced paresthesiae in the lower extremities and all suffered from insomnia. The disorder had been present for an average of 17 years (range: 2 to 34 years). In 4 patients the symptoms occurred on a daily basis and in 2 patients they occurred 2 to 4 days each week. The complaint of leg restlessness while sitting or lying down was considered a prerequisite for inclusion in the study. In addition, the symptoms had to occur at least twice a week and to be severe enough to cause significant discomfort. To insure that the patient

From: The Neurology Service (Dr. Boghen) and the Department of Pharmacy (Mrs. Lamothe), Hôtel-Dieu de Montréal. The Louis-H. Lafontaine Hospital (Dr. Elie). The Sleep Disorders Center, Sacré-Coeur Hospital (Mr. Godbout and Dr. Montplaisir). Montréal, and the Faculty of Medicine, Université de Montréal, Montréal. Québec Received February 12, 1986. Accepted April 7, 1986

Reprint requests to: Dan Boghen, Neurology Service, Hôtel-Dieu de Montréal, 3840 St Urbain. Montréal. Québec H2W IT8 
was having a true attack and not just scattered symptoms, the current episode had to have been present for at least one month. Moreover the past history of the disease in a given patient had to warrant the assumption that the symptoms would persist without spontaneous resolution during the three months of the study period. The patients had to sign an informed consent form and to comply with the requirements of the study. Pregnant women and patients with systemic illnesses such as diabetes and liver or renal diseases were excluded.

\section{Investigational Drug}

Clonazepam tablets $0.5 \mathrm{mg}$ and identical-appearing placebo (80 MEX 12 ans 80 MEX 11 respectively, Hoffman-La Roche Ltd.) were employed.

\section{Procedure}

Of the six patients, three, picked at random, received clonazepam for four weeks and placebo for four weeks thereafter (Gl) while the other three received the same medication and for the same period of time but in reverse order (G2). The drugs were administered according to the same schedule during each of the two treatment phases. In the first week the patients received one tablet of the medication under study at 22:00 hours (or 30 minutes prior to bedtime). Subsequently, dosage was increased weekly by adding one tablet at 8:00, 12:00, and 18:00 hours for weeks two, three and four respectively. The patients and the physician were blinded to the medication prescribed. Upon admission to the study patients were required to discontinue all CNS medication. During the first four weeks following inclusion of the patients in the study no medication was administered so that a drug-free baseline evaluation could be obtained. A complete physical and biological examination was performed during this period. Special care was taken in the examination of the neurological and peripheral vascular systems. Biological evaluation consisted of complete blood count with differential, blood chemistry and urinalysis. Patients were given supplies of drugs every second week and compliance was assured by tablet counts.

\section{Measures}

During the baseline and the two experimental phases thereafter the patients rated every morning the intensity of their discomfort during the previous 24 -hour period on a five-point scale (0: none, 1: slight, 2 : moderate, 3 : severe, 4 : extreme). At the end of the baseline phase and weekly thereafter a global "clinical assessment" was made by the evaluator. The patients were classified as "improved" or "no change" on the basis of information provided by them. These data allowed a global appraisal of each treatment period.

\section{RESULTS}

All the patients complained of restlessness of the legs and insomnia. Three patients experienced leg paresthesiae. Myoclonic jerks of the legs were present in 3 patients. Fatigue was an aggravating factor in 1 patient. The family history was positive in 2 patients and possibly positive in 1 patient. The neurological examination was normal except in one patient who had a long standing history of heavy drinking, stiff gait and decreased vibration and deep tendon reflexes in the lower extremities. The only associated diseases, gout in one patient and peptic ulcer in another, were considered to be unrelated to the RLS.

Drug dosage was increased as described in "methods" in 5 patients. In one patient excessive sleepiness prevented increase of clonazepam beyond 3 tablets a day. The only side effect observed during the study was sleepiness while on clonazepam in 3 patients and while on placebo in 1 patient.

Table 1: illustrates the results of treatment. The score of 3 patients while on clonazepam and of 2 patients while on placebo was at least 1 point less than the baseline score. The 2 patients whose score was improved on placebo are among those whose score improved on clonazepam. The "clinical assessment" was in agreement with the score except in the case of patient 5 who claimed improvement on clonazepam in the absence of a significantly better score.

\section{Discussion}

The occurrence of myoclonus in RLS and the hereditary character of the syndrome have been noted before. ${ }^{1.11}$ In the present series $50 \%$ of the patients experienced myoclonus of the legs and up to $50 \%$ had a positive family history.

This study did not show clonazepam to be significantly more effective than placebo in the treatment of RLS. Two of the three patients whose score on clonazepam improved significantly when compared to baseline, improved on placebo as well. This is best understood as a reflection of the placebo

Table 1: Effect of treatment on the RLS

\begin{tabular}{|c|c|c|c|c|c|c|}
\hline \multirow[b]{2}{*}{ PATIENT } & \multirow[b]{2}{*}{$\begin{array}{l}\text { Age } \\
\text { Sex } \\
\end{array}$} & \multirow[b]{2}{*}{$\begin{array}{c}\text { Baseline } \\
\text { Score }\end{array}$} & \multicolumn{2}{|c|}{ CLONAZEPAM } & \multicolumn{2}{|c|}{ PLACEBO } \\
\hline & & & Score & $\begin{array}{l}\text { Clinical } \\
\text { Assessment }\end{array}$ & Score & $\begin{array}{c}\text { Clinical } \\
\text { Assessment }\end{array}$ \\
\hline \multicolumn{7}{|c|}{ CLONAZEPAM - PLACEBO (G1) } \\
\hline 2 & $58, \mathrm{M}$ & 2.5 & 2.11 & NC & 1.82 & NC \\
\hline 3 & $31, \mathrm{~F}$ & 1.38 & $0.23^{x}$ & I & $0.04^{x}$ & 1 \\
\hline \multicolumn{7}{|c|}{ PLACEBO - CLONAZEPAM (G2) } \\
\hline 6 & $47, F$ & 2.04 & $0.86^{x}$ & I & 3.71 & NC \\
\hline
\end{tabular}

I: improved; NC: no change

$x$ : significant change 
effect. A strong placebo effect in RLS has been found by others ${ }^{4}$ and may well be the basis of the alleged response of RLS to a variety of drugs. ${ }^{10}$ Even though a favorable response to placebo was only observed in the patients who received clonazepam first followed by placebo (G1) it is unlikely that the response to placebo can be explained by a carry-over effect of clonazepam since the plasma half-life of the latter drug is of only one or two days. A comparison of the clinical features of clonazepam responders and non-responders did not reveal any distinguishing features.

This study does not exclude the possibility that by use of a greater sample size, a more objective method of evaluating the effect of medication or a different schedule of drug administration the results would have been different. In the only other controlled study involving clonazepam, the drug was found to improve the quality of sleep and to provide relief from dysaesthesiae. ${ }^{10}$ In that study, by contrast with ours, the duration of the baseline period and of the clonazepam and placebo trials was of one week only, and the drug was administered in a single I mg dosage a half-hour before bedtime. During one week, the treatment consisted of the application of a vibratory stimulus for 15 minutes to one sural region. Interestingly, although vibration was not found to have any effect on the patient's symptoms and although there was no statistically significant difference between the effects of vibration and of clonazepam on the quality of sleep, clonazepam was considered to significantly improve the quality of sleep.

Opiates $^{5.6}$ and carbamazepine ${ }^{3.4}$ have recently been reported to have a beneficial effect on RLS. The reports dealing with opiates are anecdotal. One of the carbamazepine studies ${ }^{4}$ which involved 174 patients showed carbamazepine to be effective when compared to placebo. However many of the patients in this study were being treated with other drugs and the inclusion criteria are not clearly indicated.

Because RLS appears to be highly responsive to placebo, reliable findings on the effect of various drugs can only be obtained through rigorously controlled studies. Ideally, future research should be performed in a sleep laboratory where objective and quantitative data can be obtained thus obviating the need to rely on the inaccurate data inherent to subjective evaluations. Recently, a sleep laboratory study was used to advantage by Guilleminault and Flagg to show a beneficial effect of baclofen on sleep related "periodic leg movement". 12 A similar approach deserves a trial in the study of RLS.

\section{ACKNOWLEDGEMENTS}

Grateful acknowledgements to Dr. Jacques LeLorier for help with the methodology, to Dr. Dimitri Treymann for performing the general examinations. to Hoffman-La Roche for providing the experimental drug and to all the physicians who kindly agreed to refer their patients to us.

\section{REFERENCES}

1. Boghen D, Peyronnard JM. Myoclonus in familial restless legs syndrome. Arch Neurol 1976; 33: 368-370.

2. Cirignotta $F$, Zucconi M, Mondini S, et al. Epidemiological data on sleep disorders. Abstr 6th European Congress of Sleep Research. Zurich, March 23-26, 1982: 211.

3. Lundvall O, Abom P-E, Holm R. Carbamazepine in the restless legs syndrome. A controlled pilot study. Eur J Clin Pharmacol 1983: 25: 324-324.

4. Telstad W, Sorensen O, Larsen S, Lillevold PE. Stensrud P. Nyberg-Hansen R. Treatment of the restless legs syndrome with carbamazepine: a double blind study. BMJ 1984: 288: 443-446.

5. Hening W, Walters A, Côté L, Fahn S. Opiate response myoclonus. Ann Neurol 1983; 14: 112 Abstract.

6. Trzepacs PT, Violette EJ, Sateia MJ. Response to opioids in three patients with restless legs syndrome. Am J Psych 1984: 141: 993-995.

7. Matthews WB. Treatment of restless legs syndrome with clonazepam. Br Med J 1979: 1: 751 .

8. Boghen D. Successful treatment of restless legs with clonazepam. Ann Neurol 1980: 8: 341 .

9. Read DJ, Feest TG, Nassim MA. Clonazepam: effective treatment for restless legs syndrome in uraemia. $\mathrm{Br}$ Med $\mathrm{J}$ 1981: 283: 855-886.

10. Montagna $P$, de Bianchi LS, Fucconi M, Cirignotta F, Lugaresi E. Clonazepam and vibration in restless legs syndrome. Acta Neurol Scand 1984; 69: 428-430.

11. Hussey HH. Restless legs syndrome. JAMA 1976: 235: 2224.

12. Guilleminault C, Flagg W. Effect of baclofen on sleep-related periodic leg movements. Ann Neurol 1984: 15: 234-239. 